\title{
EFFECTIVENESS OF ACUPRESSURE THERAPY AT HE KUK (CO4) POINT FOR PAIN RELIEF IN WOMEN WITH SPONTANEOUS LABOR
}

\author{
Yeti Nurhayati'), Liana Mar'atu Sholikhah'), Tresia Umarianti²) \\ 1)Undergraduate Program in Nursing, \\ School of Health Sciences Kusuma Husada, Surakarta \\ 2)Undergraduate Program in Midwifery, \\ School of Health Sciences Kusuma Husada, Surakarta
}

\begin{abstract}
Background: Postpartum women with spontaneous rupture or episiotomy experience excessive pain. This pain may harm maternal condition such as lack of rest and postpartum blues. There are numerous pharmacologic pain relievers that can be used to treat labor pain. However, they may present the risk of toxic side effects and adverse reaction. Studies have shown that acupressure therapy is a safe and cost-effective alternative for pain reliever. However, little is known about the effectiveness of acupressure at HE KUK (Co4) point to reduce spontaneous labor pain. This study aimed to examine the effectiveness of acupresure at HE KUK point in relieving labor pain.

Subjects and Method: This was a randomized controlled trial with a sample of 34 postpartum women. The sample was divided into 17 subjects receiving acupressure at HE KUK (Co4) point in the experimental group, and 17 subjects receiving paracetamol in the control group. The independent variable was pain reliever (accupressure compared with paracetamol). The intervention was administered within 24 hours post delivery. The dependent variable was pain intensity (measured by Numeric Rating Scale). Initial pain comparability between both groups before intervention was tested by t-test. Effectiveness of acupresure relative to paracetamol in reducing pain was determined by comparing mean difference of pain intensity between both groups by $t-$ test.

Results: Pain intensity was comparable between both groups before the intervention ( $>$ $>0.05)$ confirming the success of randomization. After intervention, pain intensity was lower in the experimental group (Mean=4.41; $\mathrm{SD}=1.33$ ) than the control group (Mean=7.18; $\mathrm{SD}=0.95$ ), with Effect $\mathrm{Size}=-2.40$, indicating significant effectiveness of acupressure relative to paracetamol.
\end{abstract}

Conclusion: Acupressure at HE KUK (Co4) point is more effective than parasetamol to relieve spontaneous labor pain.

Keywords: acupressure, HE KUK (Co4), pain, spontaneus labor

\section{Correspondence:}

Yeti Nurhayati. School of Health Sciencies Kusuma Husada Surakarta, Central Java. Email: yeti_nurhayati234@yahoo.com. Mobile: 085292729539. 